of brain death. J Neurosurg 1981 ;55: 942-946.

4. Rudolf J, Haupt WF, Neveling M, Grond M. Potential pitfalls in apnea testing. Acta Neurochir (Wien) 1998; 140: 659-663.

5. Wijdicks EF. In search of a safe apnea test in brain death: is the procedure really more dangerous than we think. Arch Neurol 1995;52:338-339.

\section{The Alphabetization of Journal Articles}

I am a great believer in textual efficiency in scientific writing, but there are limits. Take for example, this sentence from a recent CJNS editorial: "The American Heart Association produced a CPG stating that ACS was a suitable indication for $\mathrm{CE}$, provided that the perioperative $\mathrm{M} / \mathrm{M}$ rate was $<3 \%$ ". ${ }^{1}$ I would like to suggest to TF that it is a PIB to have to KLE in the article to FO the meaning of the SBR.

$\mathrm{TF}=$ Tom Feasby

$\mathrm{PIB}=$ pain in the butt

$\mathrm{KLE}=$ keep looking elsewhere

$\mathrm{FO}=$ find out

SBR $=$ sentence being read

RSM = R.S. McLachlan

\section{Reference}

1. Feasby TF. Endartectomy for Asymptomatic Carotid Stenosis in the Real World. Can J Neurol Sci 2000;27:95-96.

\section{Response to The Alphabetization of Journal Articles}

I regret that RSM felt challenged by my concise style, although I noticed that he used the cryptic abbreviation CJNS himself. While he apparently found it to be a PIB to KLE, E isn't very far away in a brief editorial. I agree with Pascal, who said of a letter "I have only made this longer because I have not had the time to make it shorter". Here's to short letters, and editorials, and let's save the rain forest.

\section{Thomas E. Feasby Calgary, Alberta}

\section{Issues Relating to Functional Disability in Essential Tremor}

Essential tremor (ET) is probably not a homogeneous condition, and subtypes of ET (i.e., those forms of ET that may differ with regard to their etiology, rate of progression, prognosis or response to treatment) probably exist. ${ }^{1}$ Identification of such subtypes has importance in both clinical settings and research studies.

Cenk Akbostanci et $\mathrm{al}^{2}$ reported that ET patients with synchronous activity of antagonist muscles had greater disability than did patients with alternating activity, arguing for a separation of these two into distinct clinical subgroups of ET. While these findings are important, there are a number of methodological issues that their study raises.

First, the rating scale used by the authors ${ }^{3}$ assessed the patients' subjective complaints of tremor (i.e., self-reported disability) rather than disability as assessed using a performancebased test of function. ${ }^{4}$ Although there is a correlation between the answers on this subjective scale and more objective measures of tremor severity (e.g., the correlation, $r$, between the disability score and spirography $=0.659),{ }^{3}$ the correlation is not perfect, so that the subjective measure can not serve as a substitute for objective measures. Therefore, it would be important to establish that the two groups actually differed in terms of an objective performance-based measure of function.

The second comment relates to the issues of depression and anxiety. Although these generally are not assessed in studies of functional impairment in tremor, their impact on reported disability is significant. In the Columbia University Assessment of Disability in ET, ${ }^{4}$ we studied functional disability in 178 subjects using a tremor disability questionnaire, a performancebased test of function, a clinician-rated tremor score, quantitative computerized tremor analysis, and psychological assessments. While we found that the score on the tremor disability questionnaire was associated with the clinician's rating of a videotaped tremor examination $(\mathrm{p}<0.001)$ and the performancebased test $(\mathrm{p}<0.001),{ }^{4,5}$ it was also independently associated with depression assessed using the depression module of the Structured Clinical Interview for DSM IV $(p=0.02)$ and the Hamilton Anxiety Rating Scale score $(\mathrm{p}=0.017) .{ }^{5}$ These data suggest that depression and anxiety, independent of the severity of the tremor itself, are associated with greater reported functional disability in ET, so that these factors must be considered when assessing disability in ET.

Third, the authors reported that subjects who had synchronous activity of antagonist muscles were marginally older and had disease of longer duration than those with alternating activity. Although these differences did not reach statistical significance, this may have related to the relatively modest sample size rather than the absence of an effect. Multivariate regression analyses would help to verify the reported association between the physiological type of tremor (synchronous vs. alternating activity of antagonist muscles) and reported disability, independent of the effects of age and tremor duration.

Elan D. Louis New York, NY, USA.

\section{References}

1. Louis ED, Ford B, Barnes LF. Clinical subtypes of essential tremor. Arch Neurol 2000;57:1194 -1198.

2. Cenk Akbostanci M, Ulkatan S, Yigit A, Aydin N, Mutluer N. Differences in disability between electrophysiological subgroups of essential tremor. Can J Neurol Sci 2000;27:60-64.

3. Bain PG, Findley LJ, Atchison P et al. Assessing tremor severity. J Neuro Neurosurg Psychiatry 1993;56:868-873.

4. Louis ED, Barnes LF, Wendt KJ, et al. Validity and test-retest reliability of a disability questionnaire for essential tremor. Mov Disord 2000;15:516-523.

5. Louis ED, Barnes LF, Albert SM, et al. Predictors of functional disability in essential tremor. Mov Disord 2000 (Submitted). 